Pacific Journal of Mathematics

ON THE BOUNDARY CORRESPONDENCE OF
QUASICONFORMAL MAPPINGS OF DOMAINS BOUNDED BY

tEREnCE John ReED 


\title{
ON THE BOUNDARY CORRESPONDENCE OF QUASICONFORMAL MAPPINGS OF DOMAINS BOUNDED BY QUASICIRCLES
}

\author{
Terence J. Reed
}

\begin{abstract}
A Jordan curve $\mathscr{P}$ is a quasicircle if there exists a constant $C(1 \leqq C<\infty)$ such that the cross ratio $\left(z_{1}, z_{2}, z_{3}, z_{4}\right)$ of any four points $z_{1}, \cdots, z_{4}$ in order on $\mathscr{L}$ satisfies $\left|\left(z_{1}, z_{2}, z_{3}, z_{4}\right)\right| \leqq C$. It is shown that the boundary correspondence $f$ induced by a quasiconformal homeomorphism of two Jordan domains bounded by quasicircles satisfies $\left|\left(w_{1}, w_{2}, w_{3}, w_{4}\right)\right| \leqq A\left|\left(z_{1}, z_{2}, z_{3}, z_{4}\right)\right|^{\alpha}$, $(A \geqq 1,0<\alpha \leqq 1)$ where $w_{k}=f\left(z_{k}\right)$ and the points are in order on the boundary. A converse to this result is proved and estimates are computed in each direction.
\end{abstract}

Definition 1. A Jordan curve $\mathscr{L}$ is called a $C$-quasicircle $(1 \leqq C<\infty)$ if

$$
\left|\left(z_{1}, z_{2}, z_{3}, z_{4}\right)\right|<C
$$

for any four points $z_{1}, \cdots, z_{4}$ in order on $\mathscr{L}$.

Since cross ratios are invariant under Möbius transformations we will assume without loss of generality from now on that $\mathscr{L}$ contains $\infty$ whence we may assume $z_{4}=\infty$ so that (1) becomes $\left|\left(z_{1}, z_{2}, z_{3}\right)\right| \leqq C$ or more graphically,

$$
\left|z_{1}-z_{2}\right| \leqq C\left|z_{1}-z_{3}\right|
$$

This definition and the observation of the importance of these curves to the theory of quasiconformal mappings are due to Ahlfors [1].

Definition 2. (a) We will say that a homeomorphism $f$ of a $C$ quasicircle $\mathscr{L}$ onto a Jordan curve $\mathscr{L}^{\prime}$ is $(A, \alpha)$-upper quasisymmetric, $A \geqq 1,0<\alpha \leqq 1(A, \alpha$ constants $)$ if

$$
\left|\left(w_{1}, w_{2}, w_{3}, w_{4}\right)\right| \leqq A\left|\left(z_{1}, z_{2}, z_{3}, z_{4}\right)\right|^{\alpha}
$$

for any four points $z_{1}, z_{2}, z_{3}, z_{4}$ in order on $\mathscr{L}$ and where $w_{k}=f\left(z_{k}\right)$, $k=1,2,3,4$.

(b) If we replace (2) by

$$
\left.B\left|\left(z_{1}, z_{2}, z_{3}, z_{4}\right)\right|^{\beta} \leqq \mid w_{1}, w_{2}, w_{3}, w_{4}\right) \mid
$$

under the same conditions and for some constants $B$ and $\beta, \beta \geqq 1$, $0<B \leqq 1$ then we will call $f(B, \alpha)$-lower quasisymmetric. 
Again in what follows and without loss of generality we will assume that $\infty \in \mathscr{L}, \mathscr{L}^{\prime}$ and that $f(\infty)=\infty$ in which case (2) and (3) may be replaced by

$$
\left|\left(w_{1}, w_{2}, w_{3}\right)\right| \leqq A\left|\left(z_{1}, z_{2}, z_{3}\right)\right|^{\alpha}
$$

and

$$
B\left|\left(z_{1}, z_{2}, z_{3}\right)\right|^{\beta} \leqq\left|\left(w_{1}, w_{2}, w_{3}\right)\right|
$$

respectively and where $\left(z_{1}, z_{2}, z_{3}\right)=\left(z_{1}, z_{2}, z_{3}, \infty\right)$, etc.

The term quasisymmetric is adapted from the term as applied to real functions of a real variable. We have

Definition 3. $f$ is called $\rho$-quasisymmetric or simply quasisymmetric if

$$
1 / \rho \leqq(f(x+t)-f(x)) /(f(x)-f(x-t)) \leqq \rho
$$

for some constant $\rho \geqq 1$ and all $x$ and for all $t \neq 0$.

In Theorem 3.1 we will easily show that for the real case, (2)', $(3)^{\prime}$ and (4) are equivalent.

REMARKs. The following statements are rather immediate consequences of the above definitions.

1. If $f$ is an $(A, \alpha)$-upper quasisymmetric mapping of a $C$-quasicircle $\mathscr{L}$ then $f(\mathscr{L})$ is an $A C^{\alpha}$-quasicircle.

2. If $f$ is an $(A, \alpha)$-upper quasisymmetric map of Jordan curves then $f^{-1}$ is an $\left(A^{-1 / \alpha}, 1 / \alpha\right)$-lower quasisymmetric map of the same curves in reverse order.

3. If $f_{1}$ and $f_{2}$ are $\left(A_{1}, \alpha_{1}\right)$ and $\left(A_{2}, \alpha_{2}\right)$-upper quasisymmetric mappings respectively then the composition $f_{1} \circ f_{2}$ is $\left(A_{1} A_{2}^{\alpha_{1}}, \alpha_{1} \alpha_{2}\right)$-upper quasisymmetric.

Similar remarks hold for lower quasisymmetric functions. The following lemmas are fundamental to this paper.

The first lemma incorporates the main results of the paper of Beurling and Ahlfors [3] where also originated Definition 3 above.

Lemma 1. (a) The boundary correspondence $f$ induced by a $K$ quasiconformal $F$ of the upper half plane onto itself with $F(\infty)=\infty$ is $\rho$-quasisymmetric.

(b) If $f$ is $\rho$-quasisymmetric then there exists a $K$-quasiconformal mapping $F$ of the upper half plane onto itself such that $F$ restricted to the real line is $f$.

Let $\mathscr{F}$ denote the class of quasiconformal self homeomorphisms $F$ 
of the upper half plane with $F(\infty)=\infty$. Set $\rho(F)=\operatorname{Inf}\{\rho \mid$ the restriction of $F \in \mathscr{F}$ to the real line is $\rho$-quasisymmetric $\}$ and $\Phi(K)=$ $\operatorname{Sup}\{\rho(F) \mid F \in \mathscr{F}$ and $F$ is $K$-quasiconformal $\} . \quad \Phi(K)$ is given explicitly in $[2$, p. 65]; we have the convenient estimate

$$
\rho \leqq \Phi(K) \leqq \min \left\{16^{-1} e^{\pi K}, e^{(K-1) / .2284}\right\}
$$

from [2, p. 65] and [3] for the $\rho$ of (a) of Lemma 1.

Let $K(f)=\inf \{K \mid$ there exists a $K$ quasiconformal extension $F \in \mathscr{F}$ of $f\}$ and $\Psi(\rho)=\sup \{K(f) \mid f$ is $\rho$-quasisymmetric $\}$. The construction of $F$ in Lemma $1(\mathrm{~b})$ can be carried out so that $K \leqq \min \left\{\rho^{2}, 8 \rho\right\}$ (c.f. [3] and [5]). Thus we have the estimate

$$
\Psi(\rho) \leqq \min \left\{\rho^{2}, 8 \rho\right\} .
$$

The exact value of $\Psi(\rho)$ is not known.

Lemma 2. Let $\mathscr{D}$ be a Jordan domain with C-quasicircular boundary $\mathscr{L}$ and let $w=g(z)$ be a $K_{g}$-quasiconformal mapping of $\mathscr{D}$ onto the upper half plane. Then there exists a K-quasiconformal mapping $G$ of the plane onto itself such that $\left.G\right|_{\mathscr{S}}=g$ with

$$
K=K_{g} \Psi(M), M=\Phi(L), L=\pi\left(1+C^{5} e^{2 \pi}\right)^{2}
$$

where $\Psi$ and $\Phi$ are the functions defined above.

Here it is clear that $K$ is a functions only of $K_{g}$ and $C$ and we will denote this $K$ sometimes by $K\left(K_{g}, C\right)$ and abbreviate this by $K(C)$ when $g$ is conformal $\left(K_{g}=1\right)$.

Lemma 2 is the reflection principle of Ahlfors [1]. We also have the following.

Lemma 3. Let $\mathscr{L}$ be a $C$ quasicircle containing $\infty$ and let $z_{1}$, $z_{2}, z_{3}$ be any three points in order on $\mathscr{L}$. Further, let $\mathscr{A}$ denote the arc $\overparen{z_{1}, z_{2}}$ and $\mathscr{B}$ the arc $\overparen{z_{3}, \infty}$ on $\mathscr{L}$. Then the module $M$ of the ring domain $\mathscr{R}$ consisting of the entire plane with boundaries $\mathscr{A}$ and $\mathscr{B}$ satisfies the inequality

$$
M<\frac{1}{2 \pi} \log 24 C\left|\frac{z_{3}-z_{1}}{z_{2}-z_{1}}\right| .
$$

If in addition,

$$
\left|z_{2}-z_{1}\right|<\frac{1}{4} C^{-2}\left|z_{3}-z_{2}\right|
$$

then we have the lower estimate 


$$
\frac{1}{2 \pi} \log \frac{1}{4 C^{2}}\left|\frac{z_{3}-z_{1}}{z_{2}-z_{1}}\right| \leqq M .
$$

In particular if $\mathscr{L}$ is the real line and $\mathscr{A}=(-1,0), \mathscr{B}=(r, \infty)$ then the module $M(r)$ or $\mathscr{R}=\mathscr{R}_{r}$ satisfies

$$
\frac{1}{2 \pi} \log (1+r) \leqq M(r) \leqq \frac{1}{2 \pi} \log 24(1+r) .
$$

Proof. The module of a ring domain $\mathscr{R}$ (homeomorph of an open annulus) is $(2 \pi)^{-1} \log \left(r_{2} / r_{1}\right)$ where $r_{1}$ and $r_{2}$ are the inner and outer radii respectively of an annulus conformally equivalent to $\mathscr{R}$. From Künzi [4, p. 7]

$$
M \leqq \frac{1}{2 \pi} \log \Theta\left(\left|\frac{z_{3}-z_{2}}{z_{2}-z_{1}}\right|\right)
$$

where $(2 \pi)^{-1} \log \Theta(r)$ is the module of the ring domain $\mathscr{R}_{r}$ with boundaries $(-1,0)$ and $(r, \infty), r>0$. From the known inequality $([4, \mathrm{p} .8])$,

$$
\Theta(r)<16 r+8,
$$

we have

$$
M \leqq \frac{1}{2 \pi} \log \left(16\left|\frac{z_{3}-z_{2}}{z_{2}-z_{1}}\right|+8\right) \leqq \frac{1}{2 \pi} \log 24 C\left|\frac{z_{3}-z_{1}}{z_{2}-z_{1}}\right|
$$

where in the last step, quasicircularity was used twice. We have proved (8).

Now assume (9). In this case, $z \in \mathscr{A}$ implies by quasicircularity that $\left|z-z_{2}\right|,\left|z-z_{1}\right| \leqq C\left|z_{2}-z_{1}\right|$ whence

$$
\begin{aligned}
\left|z-\frac{1}{2}\left(z_{2}+z_{1}\right)\right| & \leqq \frac{1}{2}\left(\left|z-z_{2}\right|+\left|z-z_{1}\right|\right) \\
& \leqq C\left|z_{2}-z_{1}\right| .
\end{aligned}
$$

Let $r_{1}=C\left|z_{2}-z_{1}\right|$. Now if $z \in \mathscr{B}$ then $\left|z-z_{2}\right| \geqq C^{-1}\left|z_{3}-z_{2}\right|$ so that

$$
\begin{gathered}
\left|z-\frac{1}{2}\left(z_{2}+z_{1}\right)\right|>\left|z-z_{2}\right|-\frac{1}{2}\left|z_{2}-z_{1}\right| \\
\geqq \frac{1}{C}\left|z_{3}-z_{2}\right|-\frac{1}{2 C^{2}}\left|z_{3}-z_{2}\right| \geqq \frac{1}{2 C}\left|z_{3}-z_{2}\right|
\end{gathered}
$$

where in the last step we have used (9). Set $r_{2}=2 C^{-1}\left|z_{3}-z_{2}\right|$, then (9) assures us that $r_{2}>r_{1}$. We now have an annulus $\mathscr{A}$ of center $2^{-1}\left(z_{2}+z_{1}\right)$ and of inner and outer radii respectively $r_{2}$ and $r_{1}$ contained in the ring domain $\mathscr{R}$. By the comparison theorem for modules we have 


$$
\begin{aligned}
M & >\frac{1}{2 \pi} \log \frac{r_{2}}{r_{1}}=\frac{1}{2 \pi^{2}} \log \frac{1}{2 C^{2}}\left|\frac{z_{3}-z_{2}}{z_{2}-z_{1}}\right| \\
& >\frac{1}{2 \pi} \log \frac{1}{2 C^{2}}\left|\frac{z_{3}-z_{1}}{z_{2}-z_{1}}\right|
\end{aligned}
$$

where in the last step we have used the inequality

$$
\begin{aligned}
\left|z_{3}-z_{2}\right| & \geqq\left|z_{3}-z_{1}\right|-\left|z_{2}-z_{1}\right| \geqq\left|z_{3}-z_{1}\right|-C^{-2}\left|z_{3}-z_{2}\right| \\
& \geqq\left|z_{3}-z_{1}\right|-\left|z_{3}-z_{2}\right| .
\end{aligned}
$$

This proves (10).

This right hand side of (11) results from letting $z_{1}=-1, z_{2}=0$, $z_{3}=1$ and $C=1$. The right hand side of (11) follows by applying the comparison theorems for modules to the annulus of inner radius $1 / 2$, outer radius $r+1 / 2$ and center $(-1 / 2,0)$ contained in $\mathscr{A}$.

We are now able to relate the types of quasisymmetry previously defined.

THEOREM 1. (a) If the real function $f$ is $(A, \alpha)$-upper (or $(B, \beta)$ lower) quasisymmetric on the real line with $f(\infty)=\infty$ then $f$ is $\rho$ quasisymmetric and $\rho$ depends only on $A$ and $\alpha$ (or $B$ and $\beta$ ).

(b) If $f$ is $\rho$-quasisymmetric then $f$ is $(A, \alpha)$-upper and $(B, \beta)$ lower quasisymmetric. $A, \alpha, B$ and $\beta$ and depend only on $\rho$.

Proof. For (a) it is easier to suppose first that $f$ is $(B, \beta)$-lower quasisymmetric. If we let $z_{3}=x+t, z_{2}=x, z_{1}=x-t$ and

$$
Q=(f(x+t)-f(x)) /(f(x)-f(x-t))
$$

then from $(3)^{\prime}, B 2^{-\beta} \leqq 1 /(1+Q)$ whence $Q \leqq 2^{\beta} / B-1$ and we may take

$$
\rho=2^{\beta} / B-1
$$

in Definition 3 (it is clearly sufficient to demonstrate only half of the inequality (4)). To obtain $\rho$-quasisymmetry from upper quasisymmetry directly is not easy. However if $f$ is $(A, \alpha)$-upper quasisymmetric then $f^{-1}$ is $\left(A^{-1 / \alpha}, 1 / a\right)$-lower quasisymmetric which in turn is $\rho$-quasisymmetric which $\rho$ given in (15) and $B=A^{-1 / \alpha}, \beta=1 / \alpha$. By Lemma 1 (b), $f^{-1}$ may be extended to a $\Psi(\rho)$-quasiconformal mapping $F^{-1}$ of the upper half plane onto itself, $F$ is also $\Psi(\rho)$ quasisymmetric ([2] or [6]) and its restriction $f$ by Lemma 1 (a) is $\rho^{\prime}$-quasisymmetric with $\rho^{\prime}=\Phi(\Psi(\rho)) . \quad \rho^{\prime}$ clearly depends only on $A, \alpha$ and estimates on $\rho^{\prime}$ are easily recovered from (5), (6) and (15).

To prove (b) we observe by Lemma 1 (b) that $f$ has a $K$-quasiconformal extension $F$ to the upper half plane with $K=\Psi(\rho) . \quad F$ may be normalized by a Möbius transformation so that $F(0)=0, F(1)=1$. 
The quasisymmetry (of any type) and the quasiconformality of $F$ are unaffected by this. Let $r=\left(z_{3}-z_{2}\right) /\left(z_{2}-z_{1}\right)$, and $r^{\prime}=\left(w_{3}-w_{2}\right) /\left(w_{2}-w_{1}\right)$ where $w_{k}=f\left(z_{k}\right), k=1,2,3$; then $r, r^{\prime}>0$. Further let $M_{z}$ be the module of the ring domain $R_{r}$ and $M_{w}$ the module of $R_{r^{\prime}}=F\left(R_{r}\right)\left(R_{r}\right.$ is defined in the proof of Lemma 3). By (11) of Lemma 3,

$$
\left(\frac{1}{2 \pi}\right) \log \left(\frac{\left(z_{3}-z_{1}\right)}{\left(z_{2}-z_{1}\right)}\right) \leqq M_{z}
$$

and

$$
M_{w} \leqq\left(\frac{1}{2 \pi}\right) \log \left(24 \frac{\left(w_{3}-w_{1}\right)}{\left(w_{2}-w_{1}\right)}\right)
$$

and by quasiconformality, $M_{z} \leqq K M_{w}$. Combining these three inequalities and simplifying gives us

$$
\frac{w_{2}-w_{1}}{w_{3}-w_{1}} \leqq 24\left(\frac{z_{2}-z_{1}}{z_{3}-z_{1}}\right)^{1 / K}
$$

whence $f$ is $(A, \alpha)$-upper quasisymmetric with $A=24$ and $\alpha=1 / K=$ $1 / \Psi(\rho)$. Lower quasisymmetry is established in a similar fashion.

We now state the main results of this paper. In the proofs we will assume without loss of generality that $\infty \in \mathscr{L}, \mathscr{L}^{\prime}$ and that $f(\infty)=\infty$ (hence that $F(\infty)=\infty$ ).

THEOREM 2. Let $F$ be a K-quasiconformal homeomorphism of the plane onto itself then its restriction $f$ to a mapping of a $C$-quasicircle $\mathscr{L}$ onto a $C^{\prime}$-quasicircle $\mathscr{L}^{\prime}$ is $(S, 1 / K)$-upper quasisymmetric and $(T, K)$-lower quasisymmetric with

$$
\begin{aligned}
& S=\max \left\{24 C^{\prime}\left(4 C^{2}\right)^{1 / K},\left(4 C^{2}+1\right)^{1 / K} C\right\} \\
& T=\min \left\{\left(4 C^{2}+1\right)^{-1} C^{\prime-1}, 4^{-1} C^{-2}(24 C)^{-K}\right\} .
\end{aligned}
$$

We will denote the right hand sides by $S\left(C, C^{\prime}, K\right)$ and $T\left(C, C^{\prime}, K\right)$ respectively.

Theorem 3. (a) Let $f$ be an $(A, \alpha)$-upper quasisymmetric homeomorphism of a $C$-quasicircle $\mathscr{L}$ onto a $C^{\prime}$-quasicircle $\mathscr{L}^{\prime}$ then there is an extension of $f$ to a $K$-quasiconformal mapping $F$ of the plane onto itself $\left(f=\left.F\right|_{\mathscr{C}}\right)$ with

$$
K=K(C) \Psi\left(\rho\left(A_{0}, \alpha_{0}\right)\right) K\left(C^{\prime}\right)
$$

where $K(C)$ is defined in Lemma 3.2 and

$$
\begin{aligned}
& A_{0}=S\left(C^{\prime}, 1, K\left(C^{\prime}\right)\right) \cdot A^{1 / K\left(C^{\prime}\right)} \cdot S(1, C, K(C))^{\alpha / K\left(C^{\prime}\right)}, \\
& \alpha_{0}=\alpha / K(C) \cdot K\left(C^{\prime}\right)
\end{aligned}
$$


and where the function $\Psi$ has been defined previously.

(b) Let $f$ be a $(B, \beta)$-lower quasisymmetric homeomorphism of a C-quasicircle $\mathscr{L}$ onto a $C^{\prime}$-quasicircle $\mathscr{L}^{\prime}$ then there is an extension of $f$ to a $K$-quasiconformal mapping $F$ of the plane onto itself $(f=F \mid \chi)$ with

$$
K=K(C) \Psi\left(\sigma\left(B_{0}, \beta_{0}\right)\right) K\left(C^{\prime}\right)
$$

where

$$
\begin{aligned}
& B_{0}=T\left(C^{\prime}, 1, K\left(C^{\prime}\right)\right)^{\beta K\left(C^{\prime}\right)} B^{K\left(C^{\prime}\right)} T(1, C, K(C)), \\
& \beta_{0}=\beta \cdot K(C) \cdot K\left(C^{\prime}\right) .
\end{aligned}
$$

The function $\rho(A, \alpha)$ is the $\rho$ of Theorem $1(a)$ and $\sigma(B, \beta)$ is similarly defined.

Proof of Theorem 2. Let $z_{1}, z_{2}, z_{3}$ be three points in order on $\mathscr{L}$ and $w_{k}=f\left(z_{k}\right), k=1,2,3$. Let $M_{z}$ be the modulus of the ring domain $\mathscr{R}_{z}$ obtained by removing the ares $z_{1}, z_{2}$ and $z_{3}, \infty$ from $\mathscr{L}$. Let $R_{w}=$ $F\left(\mathscr{R}_{z}\right)$ and $M_{w}$ be the module of $\mathscr{R}_{w}$. First we note that

$$
K^{-1} M_{z} \leqq M_{w} \leqq K M_{z} \text {. }
$$

We consider the two cases

1. $\left|w_{2}-w_{1}\right| \leqq 1 / 4 C^{-2}\left|w_{3}-w_{2}\right|$. Here we use the right hand side of (19) and (10) of Lemma 3 to discover that

$$
\begin{aligned}
\frac{1}{2 \pi} \log & \frac{1}{4 C^{\prime 2}}\left|\frac{w_{3}-w_{1}}{w_{2}-w_{1}}\right| \leqq M_{w} \\
& \leqq K M_{z} \leqq \frac{K}{2 \pi} \log 24 C\left|\frac{z_{3}-z_{1}}{z_{2}-z_{1}}\right|
\end{aligned}
$$

which implies that

$$
\frac{1}{4 C^{\prime 2}(24 C)^{K}}\left|\frac{z_{2}-z_{1}}{z_{3}-z_{1}}\right|^{K} \leqq\left|\frac{w_{2}-w_{1}}{w_{3}-w_{1}}\right| .
$$

2. $\left|w_{2}-w_{1}\right| \geqq 1 / 4 C^{-2}\left|w_{3}-w_{2}\right|$. Then

$$
\left|\frac{w_{3}-w_{1}}{w_{2}-w_{1}}\right| \leqq \frac{\left|w_{3}-w_{2}\right|+\left|w_{2}-w_{1}\right|}{\left|w_{2}-w_{1}\right|} \leqq 4 C^{2}+1
$$

From quasicircularity $\left|z_{3}-z_{1}\right| \geqq\left(C^{\prime}\right)^{-1}\left|z_{2}-z_{1}\right|$ so that from this and (21),

$$
\left|\frac{w_{3}-w_{1}}{w_{2}-w_{1}}\right| \leqq\left(4 C^{2}+1\right) \frac{C^{\prime K}}{C^{\prime K}} \leqq\left(4 C^{2}+1\right) C^{\prime K}\left|\frac{z_{1}-z_{3}}{z_{2}-z_{3}}\right|^{K}
$$


whence

$$
\frac{1}{\left(4 C^{2}+1\right) C^{\prime K}}\left|\frac{z_{2}-z_{1}}{z_{3}-z_{1}}\right|^{K} \leqq\left|\frac{w_{2}-w_{1}}{w_{3}-w_{1}}\right| .
$$

Combining (20) and (21) we have the assertion (16) for $B$ and $\beta$. The estimates for $A$ and $\alpha$ follow in an entirely analogous manner.

Proof of Theorem 3. Let $\mathscr{D}$ be one of the simply connected domains on the Riemann sphere $\mathscr{S}$ determined by $\mathscr{L}$ and let $\mathscr{D}^{\prime}$ be the simply connected domain determined by $\mathscr{L}^{\prime}$ which is chosen so that $f$ is sense preserving with respect to $\mathscr{D}$ and $\mathscr{D}^{\prime}$. There is a conformal mapping $G$ of $\mathscr{D}$ onto the upper half plane $\mathscr{C}$. $G$ may be extended by Lemma 2 to a $K(C)$-quasiconformal mapping of $\mathscr{S}$ onto itself and mapping $\mathscr{L}$ onto the real line $\mathscr{L}_{0}$. Let $g=\left.G\right|_{\mathscr{L}}$. According to Theorem $2 g^{-1}$ is $\left(S(1, C, K(C)), K(C)^{-1}\right)$-upper quasisymmetric $\left(G^{-1}\right.$ is $K(C)$-quasisymmetric and $\mathscr{L}_{0}$ is a 1-quasicircle). Similarly we may construct a $K\left(C^{\prime}\right)$-quasiconformal mapping $G^{\prime}$ of $\mathscr{S}$ onto itself which is conformal on $\mathscr{D}^{\prime}$ and whose restriction $g^{\prime}$ on $\mathscr{L}$ maps $\mathscr{L}$ onto $\mathscr{L}_{0}$ and $g^{\prime}$ is $\left(S\left(C^{\prime}, 1, K\left(C^{\prime}\right)\right), K\left(C^{\prime}\right)^{-1}\right)$-upper quasisymmetric.

According to Remarks 2 and 3 the mapping $h=g^{\prime} \circ f \circ g^{-1}$ is $\left(A_{0}\right.$, $\left.\alpha_{0}\right)$-upper quasisymmetric with $\alpha_{0}=\alpha_{0}\left(\alpha, C, C^{\prime}\right)=\alpha K(C)^{-1} K\left(C^{\prime}\right)^{-1}$ and

$$
\begin{aligned}
A_{0} & =A_{0}\left(A, \alpha, C, C^{\prime}\right) \\
& =S\left(C^{\prime}, 1, K\left(C^{\prime}\right)\right) \cdot A^{1 / K\left(C^{\prime}\right)} \cdot S(1, C, K(C))^{\alpha / K\left(C^{\prime}\right)} .
\end{aligned}
$$

The mappings constructed above may be chosen so that $h(\infty)=\infty$; in this case $h$ is $\rho$-quasisymmetric with $\rho=\rho\left(A_{0}, \alpha_{0}\right)$. Now according to Lemma 1 (b) $h$ has a $\Psi\left(\rho\left(A_{0}, \alpha_{0}\right)\right)$ quasiconformal extension $H: \mathscr{S} \rightarrow \mathscr{S}$. The desired extension $F$ of $f$ may now be set equal to $G^{\prime-1} \circ H \circ G$ which is now $K(C) \Psi\left(\rho\left(A_{0}, \alpha\right)\right) K\left(C^{\prime}\right)$-quasiconformal thus finishing the proof of the theorem.

Part (b) of Theorem 3 is proved in a similar manner.

Recently, S. Rickman [6] has obtained results similar to those proved in the last section of this paper. Here, we sacrifice the more general considerations of Rickman to obtain the two sided extension of Theorem 3 and the estimates exhibited in both Theorems 2 and 3.

\section{REFERENCES}

1. L. Ahlfors, Quasiconformal reflections, Acta Math. 109 (1963), 291-301.

2. - Lectures on Quasiconformal Mappings, Van Nostrand, (1966).

3. A. Beurling and L. Ahlfors, The boundary-correspondence under quasiconformal mappings, Acta Math. 96 (1956). 
4. H. P. Künzi, Quasikonforme Abbildungen, Springer, (1960).

5. T. J. Reed, Quasiconformal mappings with given boundary values, Duke Math. J. 33 (1966), 459-464.

6. S. Rickman, Quasiconformally equivalent curves, Duke Math J. (to appear)

Received April 18, 1968, and in revised from July 5, 1968. This research was supported in part by the National Science Foundation, Contract NSF-GP-6865, at the University of Colorado and forms an extension of a portion of the authors doctoral dissertation performed at the University of Minnesota under the direction of Professor Edgar Reich. 



\section{PACIFIC JOURNAL OF MATHEMATICS}

\section{EDITORS}

\author{
H. ROYDEN \\ Stanford University \\ Stanford, California \\ R. R Phelps \\ University of Washington \\ Seattle, Washington 98105
}

\author{
J. Dugundui \\ Department of Mathematics \\ University of Southern California \\ Los Angeles, California 90007
}

RICHARD ARENS

University of California

Los Angeles, California 90024

\section{ASSOCIATE EDITORS}
E. F. BeCKENBACH
B. H. NeUmanN
F. WolF
K. YosidA

\section{SUPPORTING INSTITUTIONS}

\author{
UNIVERSITY OF BRITISH COLUMBIA \\ CALIFORNIA INSTITUTE OF TECHNOLOGY \\ UNIVERSITY OF CALIFORNIA \\ MONTANA STATE UNIVERSITY \\ UNIVERSITY OF NEVADA \\ NEW MEXICO STATE UNIVERSITY \\ OREGON STATE UNIVERSITY \\ UNIVERSITY OF OREGON \\ OSAKA UNIVERSITY \\ UNIVERSITY OF SOUTHERN CALIFORNIA
}

\author{
STANFORD UNIVERSITY \\ UNIVERSITY OF TOKYO \\ UNIVERSITY OF UTAH \\ WASHINGTON STATE UNIVERSITY \\ UNIVERSITY OF WASHINGTON

$* * * * *$
AMERICAN MATHEMATICAL SOCIETY
CHEVRON RESEARCH CORPORATION
TRW SYSTEMS
NAVAL WEAPONS CENTER

The Supporting Institutions listed above contribute to the cost of publication of this Journal, but they are not owners or publishers and have no responsibility for its content or policies.

Mathematical papers intended for publication in the Pacific Journal of Mathematics should be in typed form or offset-reproduced, double spaced with large margins. Underline Greek letters in red, German in green, and script in blue. The first paragraph or two must be capable of being used separately as a synopsis of the entire paper. It should not contain references to the bibliography. Manuscripts, in duplicate if possible, may be sent to any one of the four editors. Please classify according to the scheme of Math. Rev. 36, 1539-1546. All other communications to the editors should be addressed to the managing editor, Richard Arens, University of California, Los Angeles, California, 90024.

50 reprints are provided free for each article; additional copies may be obtained at cost in multiples of 50 .

The Pacific Journal of Mathematics is published monthly. Effective with Volume 16 the price per volume (3 numbers) is $\$ 8.00$; single issues, $\$ 3.00$. Special price for current issues to individual faculty members of supporting institutions and to individual members of the American Mathematical Society: $\$ 4.00$ per volume; single issues $\$ 1.50$. Back numbers are available.

Subscriptions, orders for back numbers, and changes of address should be sent to Pacific Journal of Mathematics, 103 Highland Boulevard, Berkeley, California, 94708.

PUBLISHED BY PACIFIC JOURNAL OF MATHEMATICS, A NON-PROFIT CORPORATION

Printed at Kokusai Bunken Insatsusha (International Academic Printing Co., Ltd.), 7-17. Fujimi 2-chome, Chiyoda-ku, Tokyo, Japan. 


\section{Pacific Journal of Mathematics}

Vol. 28, No. 3

May, 1969

Jon F. Carlson, Automorphisms of groups of similitudes over $F_{3} \ldots \ldots \ldots$

W. Wistar (William) Comfort, Neil Hindman and Stelios A. Negrepontis,

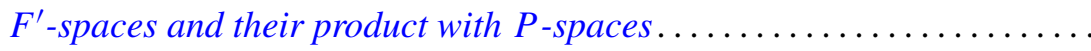

Archie Gail Gibson, Triples of operator-valued functions related to the unit

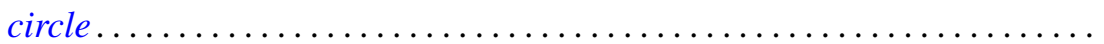

David Saul Gillman, Free curves in $E^{3}$

E. A. Heard and James Howard Wells, An interpolation problem for

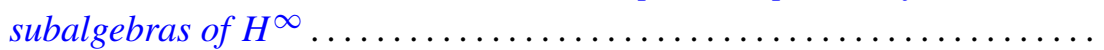

Albert Emerson Hurd, A uniqueness theorem for weak solutions of symmetric

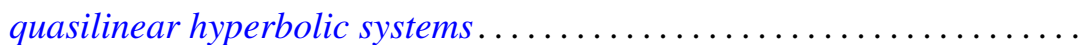

E. W. Johnson and J. P. Lediaev, Representable distributive Noether

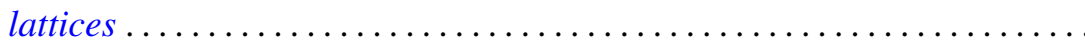

David G. Kendall, Incidence matrices, interval graphs and seriation in

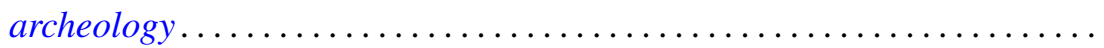
565

Robert Leroy Kruse, On the join of subnormal elements in a lattice ....... 571

D. B. Lahiri, Some restricted partition functions; Congruences modulo 3 .... 575

Norman D. Lane and Kamla Devi Singh, Strong cyclic, parabolic and conical differentiability........................................

William Franklin Lucas, Games with unique solutions that are

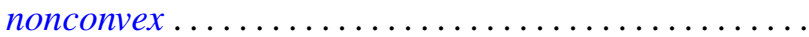

Eugene A. Maier, Representation of real numbers by generalized geometric series.

Daniel Paul Maki, A note on recursively defined orthogonal polynomials ...

Mark Mandelker, $F^{\prime}$-spaces and z-embedded subspaces ...

James R. McLaughlin and Justin Jesse Price, Comparison of Haar series with gaps with trigonometric series

Ernest A. Michael and A. H. Stone, Quotients of the space of irrationals ....

William H. Mills and Neal Zierler, On a conjecture of Golomb ...

J. N. Pandey, An extension of Haimo's form of Hankel convolutions ...

Terence John Reed, On the boundary correspondence of quasiconformal mappings of domains bounded by quasicircles...

Haskell Paul Rosenthal, A characterization of the linear sets satisfying Herz's criterion.

George Thomas Sallee, The maximal set of constant width in a lattice...

I. H. Sheth, On normaloid operators

James D. Stasheff, Torsion in BBSO ...

Billy Joe Thorne, A - P congruences on Baer semigroups.

Robert Breckenridge Warfield, Jr., Purity and algebraic compactness for

modules... 